\title{
LA RACIONALIDAD JUDICIAL EN SEDE CONSTITUCIONAL*
}

\section{THE JUDICIAL RATIONALITY IN CONSTITUTIONAL STAGE}

\author{
Julio César MuÑoz MendiolA*
}

\section{Resumen:}

En este trabajo se defiende una postura intermedia acerca de la racionalidad en la toma de decisiones de un juez constitucional, ello, a través del desarrollo de un modelo teórico denominado tesis del restrictor cognitivo, el cual se caracteriza por una serie de parámetros objetivos que constriñen y orientan cognitivamente el proceso de decisión en sede constitucional, con la finalidad de establecer una racionalidad procedimental que reduzca los espacios de subjetividad y arbitrariedad del juzgador constitucional.

\section{Palabras clave:}

Juez constitucional, elección racional, decisión judicial, restrictor cognitivo, racionalidad procedimental.

\begin{abstract}
:
This paper defends an intermediate position on the rationality of a constitutional judge's decision making, through the development of a theoretical model called the cognitive restrictor thesis, which is characterized by a series of objective parameters that cognitively construct and guide the decision making process in a constitutional venue, with the purpose of establishing a

Artículo recibido el 24 de junio de 2019 y aceptado para su publicación el 10 de julio de 2020. Ganador del IV Concurso de Investigación en Filosofía del Derecho de Estudiantes de Posgrado: paradigmas emergentes en derecho y filosofía jurídica.

** Abogado constitucionalista y coordinador de un observatorio de jurisprudencia, licenciado y maestro por la Facultad de Derecho de la UNAM. ORCID: http:// orcid.org/0000-0002-8769-7984 . correo electrónico: juliobono@icloud.com página web: https://derechoydesarrollosostenible.com/observatorio-judicial
\end{abstract}


procedural rationality that reduces the spaces of subjectivity and arbitrariness of the constitutional judge.

\section{Keywords:}

Constitutional Judge, Rational Choice, Judicial Decision, Cognitive Restrictor, Procedural Rationality. 
SumARIO: I. Introducción. II. Epistemología jurídica y razonamiento judicial. III. Paralelismo de la elección racional y la decisión judicial constitucional. IV. La tesis del restrictor cognitivo y su vinculación con la decisión del juez constitucional. V. Conclusiones. VI. Futuras Investigaciones. VII. Referencias.

\section{INTRODUCCIÓN}

Las decisiones judiciales pueden encontrarse entre la racionalidad y la irracionalidad, ${ }^{1}$ pues una decisión puede ser tanto emotiva como consiente, entonces, se hablará de que es subjetiva u objetiva respectivamente. No obstante, la mayoría de las corrientes que se refieren a la decisión judicial han dejado de lado el proceso mediante el cual un juzgador toma sus decisiones o, en su caso, no lo han explorado suficientemente. En este caso, un juez constitucional enfrenta procesos más complejos, principalmente, por el tipo de asuntos que llegan a una magistratura constitucional, ya que se enfrenta a dilemas de tipo moral, político y social que no sólo afectan al ámbito del Derecho, sino que trascienden, además, a la vida de las personas y la sociedad en general. ${ }^{2}$

1 Estos extremos se discuten en las posiciones que refutan en general la existencia de racionalidad en el Derecho y, en específico, en la decisión judicial, en donde las posturas que sostienen la existencia de racionalidad como una categoría de análisis se basarán en: 1) criterios de claridad y consistencia conceptual; 2) criterio de consistencia normativa; 3) criterio de situación; 4) criterio respecto a la lógica deductiva; 5) criterio respecto de la argumentación; y 6) criterios de consistencia argumentativa y coherencia. Véase Bernal Pulido, Carlos, El derecho de los derechos. Escrito sobre la aplicación de los derechos fundamentales, Bogotá, Universidad Externado de Colombia, 2005, pp. 63-64.

2 La impartición de justicia en general tiene una incidencia directa en la vida de las personas y en la sociedad, pero, en sede constitucional, esa incidencia será más amplia, por ejemplo, cuando una magistratura constitucional decide sobre la constitucionalidad del aborto, esa decisión afecta y trasciende a todas las mujeres que están a favor o en contra del aborto, inclusive, trasciende a los jueces ordinarios que aplicaban la ley que prohibía el aborto. En ese sentido, el caso norteamericano es paradigmático, pues lo que decide la Corte Suprema Norteamericana en ocasiones se convierte en un superprecedente que, aunado a otros factores, incidirá para 
Además, si se toma en cuenta que las prácticas judiciales son el medio ambiente en donde la sincronización y la propagación de interacción entre diferentes agentes constituyen una red compleja, la cual, de forma autoorganizativa y codependiente, hace surgir la cognición situada que está en la base de las decisiones judiciales. ${ }^{3}$

Por tanto, el proceso de decisión en una magistratura constitucional funciona como un restrictor cognitivo (en adelante RC), el cual determinará la racionalidad en la toma de decisiones de un juez constitucional o, por lo menos, reducirá los espacios para la subjetividad, la arbitrariedad y las posiciones estratégicas por parte de este operador constitucional. En este punto, es importante señalar que las decisiones judiciales se encuentran en una postura extremadamente realista o, en su polo contrario, en una postura exageradamente idealista. En el primer caso, se sostendrá que un juez constitucional está siempre determinado por su ideología y subjetividad, mientras que, en el segundo caso, se afirmará que existen operadores constitucionales infalibles; los cuales siempre deciden de forma correcta frente a cualquier dilema, pero, sobre todo, absolutamente alejados de ideologías y subjetividades.

Ambas posturas podrían ser correctas, pero insuficientes por lo que implican las decisiones que se toman en una magistratura constitucional, ya que generalmente repercutirán a un ámbito social. Así, estas decisiones encontrarán grandes paralelismos con las decisiones colectivas. Consecuentemente, será necesario plantear ese RC como modelo mental que determina las decisiones de los jueces constitucionales, pero, sobre todo, resaltar que esa proposición entrañará una postura realista, pues asume a este operador constitucional con posiciones subjetivas y arbitrarias hasta cierto punto; no obstante, al mismo tiempo concibe un proceso que cuenta con fuer-

impulsar o lograr cambios sociales en una proporción mayor. Sobre la importancia social de la función judicial véase Wróblewski, Jerzy, Sentido y hecho en el derecho, trad. de Leonel Castillo González, México, Fontamara, 2001, pp. 67 y ss. Sobre los superprecedentes y su incidencia social véase Ackerman, Bruce, La constitución viviente, trad. de Carlos M. Enrigue, Madrid, Marcial Pons, 2011, pp. 64 y ss.

3 Cfr. Cáceres Nieto, Enrique, "Dispraxis jurídica. Modelos mentales y constructivismo jurídico complejo", en Calle Valle, Fernando et al. (coords.), Dispraxis, 2a. ed., México, UNAM, 2012, p. 197. 
tes parámetros objetivos que, al final, determinarán cognitivamente sus decisiones.

De esta forma, el trabajo se abocará a los siguientes objetivos: 1) a partir de la epistemología jurídica aplicada, en este caso, en lo que se refiere a la complejidad del razonamiento jurídico, concretamente, al nivel de un operador constitucional, establecer la implicación cognitiva que tiene el proceso mediante el cual un juez constitucional toma sus decisiones institucionalmente; 2) proponer ciertas conexiones de las decisiones fundamentales colectivas con las decisiones en sede constitucional; 3) proponer lo conveniente de asumir una postura intermedia, en torno a la posibilidad de una racionalidad procedimental, en grados, de estas decisiones; y 4) proponer la tesis del RC, lo cual pretende abrir un nuevo espectro de estudio de las decisiones en sede constitucional.

Para el desarrollo de esos objetivos, el trabajo se dividirá en dos bloques: 1) el planteamiento teórico en torno al razonamiento jurídico y su vinculación con las decisiones judiciales en sede constitucional, así como un paralelismo con la teoría de la elección racional; y 2) la proposición de la tesis del RC, la cual establece que el proceso de toma de decisiones en esa sede, se encuentra revestido de parámetros objetivos que reducen los espacios de subjetividad y arbitrariedad de esas decisiones.

\section{EPISTEMOLOGÍA JURÍDICA Y RAZONAMIENTO JUDICIAL}

En los últimos años la epistemología jurídica ha cobrado gran importancia como una rama indispensable de la filosofía del Derecho, pues al igual que la filosofía en general, la epistemología como un área cuyo objetivo es determinar las condiciones bajo las cuales una creencia puede ser considerada verdadera y justificada, ${ }^{4}$ implica un ejercicio de análisis y reflexión que no sólo se agotará en una proposición descriptiva, sino que va más allá, ya que gran parte de su estudio se centrará también en las decisiones del Derecho, tanto por la forma en la que se han de tomar como por sus consecuencias que

4 Cáceres Nieto, Enrique, "Epistemología Jurídica..., cit., p. 2197. 
JULIO CÉSAR MUÑOZ MENDIOLA

tendrán. De esta manera, la epistemología jurídica vino a proporcionar una aplicación práctica en la tarea de justificación y comprobación; es decir, a la epistemología jurídica le interesan los procesos mediante los cuales se puede comprobar un fenómeno jurídico. ${ }^{5}$

Para el caso, el fenómeno al que se avoca este trabajo será al de las decisiones judiciales, en otras palabras, al conocimiento de los juzgadores, los cuales enarbolan una expertis en su interacción con los hechos, relaciones, mecanismos y rutinas en diferentes contextos, que los han llevado a aplicar dicho conocimiento a nuevos casos (criterio jurídico). ${ }^{6}$ Así, ese criterio se enfocará a un juzgador en específico y sólo al mecanismo mediante el cual lo aplica a la hora de tomar sus decisiones; esto es, a los jueces constitucionales y a su proceso de toma de decisiones.

Esta delimitación se justifica por dos cuestiones principalmente. La primera, en torno a que, si de manera general se acepta que un juzgador tiene modelos mentales más ricos que cualquier otro operador jurídico por diversas razones, ${ }^{7}$ entonces, coherentemente tendría que reconocerse que el modelo mental de un juzgador constitucional es, permítase la expresión, aún más técnico por su labor. Y, la segunda, en relación a que, como se verá más adelante, esta tipología de juzgadores encuentra convergencias en diferentes sistemas jurídicos a través del proceso de decisión, por lo cual, independientemente de la tradición o cultura jurídica, su forma de conocimiento de los asuntos resulta similar en su estructura y funcionamiento.

Esto último implica establecer dos presupuestos para que se pueda tomar como válida dicha premisa: 1) que el sistema jurídico donde opera esa tipología de juez se encuentre bajo el paradigma

5 En este punto, la epistemología jurídica se centrará más en identificar y analizar procedimientos confiables, los cuales servirán cómo una base o punto de partida en una tarea de conocimiento, con la finalidad de que, un hecho jurídicamente relevante, pueda considerarse verdadero y no sólo una creencia. Cuestión que es comprensible si se toma en cuenta que, los operadores jurídicos, no representan constantes uniformes a diferencia de los procesos mediante los cuales operan. Sobre procesos confiables en epistemología jurídica véase Laudan, Larry, Truth, error and criminal law, Nueva York, Cambridge University Press, 2006, pp. 6, 7 y 42.

6 Cáceres Nieto, Enrique, Pasos hacia una teoría de modelos mentales..., cit., p. 10.

7 Cfr. idem. 
del Estado Constitucional, es decir, que institucionalmente esté contemplado el control judicial, ${ }^{8}$ y 2) que desde ese diseño opere de manera más o menos fuerte ese control, además de que exista una magistratura especializada que represente la última instancia de decisión, en otras palabras, que ese control tenga la fuerza definitiva de intervenir en la limitación del poder público y político. ${ }^{9}$

Por otra parte, será indispensable definir de manera sucinta el elemento de la racionalidad, ya que tiene una especial relación con el razonamiento judicial en sede constitucional, sobre todo, para describir de mejor manera el modelo mental de un juez constitucional. Asimismo, este elemento representa para este trabajo un elemento de vinculación con la elección racional.

\section{PARALELISMO DE LA ELECCIÓN RACIONAL Y LA DECISIÓN JUDICIAL CONSTITUCIONAL}

Para hablar de racionalidad es necesario referirse a la razón, lo cual implica una cuestión de suyo compleja, al menos desde el ámbito

8 El paradigma constitucional, como categoría de análisis, es común para las tradiciones de Civil law contemporáneas, no así para las tradiciones de Common Law; no obstante, existirá una convergencia al considerarse que, aún en países de Common Law (como Inglaterra o Nueva Zelanda), sus sistemas jurídicos, ideológicamente y desde su diseño institucional, están fundados sobre la base de un régimen democrático y el respeto y garantía de los derechos fundamentales (un Estado de Derecho en sentido amplio).

9 Una aclaración pertinente es establecerse que el control judicial, en gran medida, presupone la existencia de una justicia constitucional o, si se prefiere, una jurisdicción constitucional, lo cual no implica sostener que ese control opere siempre como instancia final de decisión o de manera uniforme respecto de su intensidad; sin embargo, aún en los sistemas en donde el parlamento representa el órgano de cierre del sistema y se habla de un control judicial débil, como en Inglaterra o Nueva Zelanda, ese control se aplica e incide en la dinámica estatal. Por ejemplo, recientemente la Corte Suprema inglesa decidió que la suspensión del parlamento tenía el efecto de incumplir con las funciones constitucionales de este órgano, es decir, la suspensión era ilegal (inconstitucional), cuestión que ejemplifica como un control judicial débil puede tener una incidencia importante. Véase "Supreme Court: Suspending Parliament was Unlawful, Judges Rule", BBC News, 24 de septiembre de 2019, disponible en: https://www.bbc.com/news/uk-politics-49810261. 
JULIO CÉSAR MUÑOZ MENDIOLA

general de las ciencias sociales, porque el tránsito de la razón supeditada a la religión, a una fundada en una razón autosuficiente, estableció que la sola razón arrojaría normas adecuadas que servirían a todos por igual; ${ }^{10}$ en otras palabras, se pensó que la objetividad conceptual captaría la verdad del sujeto diluyéndolo en la generalidad. ${ }^{11}$ Ahora bien, no es pretensión justificar la razón o concederle una objetividad práctica a la manera kantiana, ${ }^{12}$ o refutar de alguna manera el individualismo metodológico, sino abordar el tema de la racionalidad reduciéndola a sus dos principales tradiciones intelectuales contemporáneas.

La primera, es la tradición que opone la razón a las pasiones y, en época más reciente, a los intereses. La segunda, la tradición referente a la elección racional, la cual se opone a las diversas formas de la irracionalidad. ${ }^{13}$ Ambas tradiciones distinguen que actuar conforme a la razón, en singular, y actuar por buenas razones, en plural, son dos cosas diferentes; por cuanto la razón es objetiva, mientras que las razones son subjetivas. ${ }^{14}$

Así, la racionalidad en la toma de decisiones y la racionalidad a la que se refiere la toma de decisiones, no es otra que aquella que se entiende como el recurso propio y exclusivo del ser humano, que consiste en el uso apropiado de la razón para elegir de la mejor manera posible ${ }^{15}$; en otras palabras, ofrecer razones cognoscibles y susten-

10 Sobre las transiciones históricas en la razón, véase Taylor, Charles, "La sola razón", trad. de Gabriel García Jolly, Revista de Filosofía Open Insight, México, vol. IV, núm. 10, julio-diciembre de 2015, pp. 207-237.

${ }_{11}$ Cfr. Palacio Díaz, Alejandro, La razón contra sí misma. Razón y justicia en siglo XX, México, Claves Latinoamericanas, 2000, p. 17.

12 Sobre la filosofía práctica kantiana y su uso en la política y el Derecho, véase Howard, Williams, "En la sombra de la crítica de la razón pura: los resultados de la filosofía crítica llevados a la filosofía legal y política de Kant", trad. de Isabel Gamero y Macarena Marey, Las Torres de Luca. International Journal of Politicial Philosophy, Madrid, vol. 7, núm. 13, 2018, pp. 63-77.

13 Elster, Jon, Razón y racionalidad, trad. de Horacio Pons, Buenos Aires, Editores Amorrortu, 2014, pp. 9-10.

14 Ibidem, p. 10.

15 Cfr. Suárez Romero, Miguel Ángel, "La argumentación jurídica y el pensamiento de Luis Recaséns Siches. Un análisis retrospectivo", Luis Recaséns Siches: Homenaje, México, UNAM, Facultad de Derecho, 2012, p. 121. 
tadas en el saber de quien las decide. En este punto, será necesario abocarse a la teoría de la elección racional, la cual se ha convertido en un recurso de las ciencias sociales, como una forma de explicar y, en cierta medida, resolver el fenómeno de las elecciones colectivas fundamentales. Esta teoría cuenta con una perspectiva analítica, es decir, se aproxima a los fenómenos sociales asumiendo que estos se pueden explicar en términos de sus partes constitutivas y de las relaciones causales que existen entre ellas. ${ }^{16}$

Así, la teoría de la elección racional se encargaría de los mecanismos causales en la acción social, los cuales están representados por las decisiones que toman los actores cuando interactúan entre sí. Consecuentemente, esas acciones humanas que se pueden describir como decisiones comparten dos propiedades generales: intencionalidad y racionalidad. ${ }^{17}$ Estas propiedades comprenderán uno de los grandes problemas de la elección racional, ya que la intencionalidad bien podría situarse en el plano de la subjetividad, en oposición al de la racionalidad que, al menos en forma de presunción, se encuentra en el campo de la objetividad.

En ese punto, la teoría de la elección racional asume una racionalidad perfecta, ${ }^{18}$ en el sentido que se perfila en situar a las personas como decisores deliberados que, no sólo eligen el mejor proceso para la toma de decisiones, sino que también eligen las decisiones más útiles para la mayoría. No obstante, la base de la mayoría de los teóricos de la elección racional se fundamenta, en mayor o menor medida, en que la racionalidad se logra sólo si se maximiza la utilidad. $^{19}$

16 Abitbol, Pablo y Botero, Felipe, "Teoría de la elección racional: estructura conceptual y evolución reciente", Revista Colombia Internacional, Colombia, núm. 62, julio-diciembre de 2005, p. 134.

17 Cfr. Idem.

18 Este concepto es desarrollado por el profesor Elster, véase Elster, Jon, Ulises y las sirenas: estudios sobre racionalidad e irracionalidad, trad. de Juan José Utrilla, México, Fondo de Cultura Económica, 1989.

${ }_{19}$ Cfr. Allingham, Michael, La teoría de la elección racional. Una breve introducción, trad. de José Ventura López, Madrid, Alianza Editorial, 2011, p. 48. 
JULIO CÉSAR MUÑOZ MENDIOLA

Por tanto, no puede pasar desapercibida la posición utilitarista que subyace a esta teoría, ${ }^{20}$ es decir, su fuerte carácter economicista, ya que, al final, las decisiones colectivas fundamentales se dirigen a normas sociales, y estas poseen un carácter orientador hacia otras normas, lo que vuelve la elección contingente porque implica que las normas son sociales sólo si satisfacen, que las mismas se compartan con otros miembros de la sociedad y que sean impuestas mediante sanciones provistas por otros. ${ }^{21}$

El punto a destacar es que la propia complejidad de las decisiones colectivas fundamentales reduce la posibilidad de elecciones únicas, infalibles, verdaderas y absolutas, ya que no existe el presupuesto de que hay un número de individuos idénticamente situados, cada uno teniendo que tomar una única decisión simultáneamente con todos los demás. ${ }^{22}$ En un sentido rawlsoniano es complejo encontrar el primer uso de la posición original que se refiere a un modelo de condiciones justas y razonables para que las partes, que son representantes racionales de ciudadanos libres e iguales, razonables y racionales, especifiquen términos justos de cooperación para regular la estructura básica social, ${ }^{23}$ ya que resulta imposible, al mismo tiempo, satisfacer tanto el bienestar de uno como el bienestar de todos.

Ahora bien, si se asume con carácter ambivalente la teoría de la elección racional, se tendrá que reconocer que es una herramienta indispensable para manifestar e integrar las siguientes interdependencias: 1) entre el bienestar de cada uno y las decisiones de todos; 2) entre el bienestar de cada uno y el bienestar de todos, y 3) entre las decisiones de cada uno y las decisiones de todos. ${ }^{24}$ En otras palabras, esta teoría no puede explicar y solucionar el gran dilema que

20 Véase un estudio completo sobre el utilitarismo en las decisiones, así como su relación con políticas públicas en Baron, Jonathan, Morality and Rational Choice, Boston, Springer, 2001, principalmente los capítulos 2, 5, 9 y 12.

${ }^{21}$ Elster, Jon, Juicios salomónicos. Las limitaciones de la racionalidad..., cit., pp. 36-37.

22 Elster, Jon, Las limitaciones del paradigma de la elección racional..., cit., p. 146.

23 Cfr. Rawls, John, El derecho de gentes y una revisión de la idea de razón pública, trad. de Hernando Valencia Villa, España, Editorial Paidós, 2001, p. 43.

24 Elster, Jon, Las limitaciones del paradigma de la elección..., cit., pp. 254 y 255. 
representa la toma de decisiones fundamentales en sociedad, pero, por lo menos, sí puede proporcionar un método o proceso racional para ello.

En este punto, cabría señalar que el éxito o fracaso de la elección racional, dependerá de la acción social, ${ }^{25}$ entendida como acciones de los agentes sociales en lo individual, pero que trascienden a la colectividad, por lo cual, realistamente, sólo aspira a justificarse mediante una sucesión de argumentos sobre respuestas plausibles. ${ }^{26}$ Consecuentemente, las elecciones racionales puedan sustentarse: 1) en un proceso de decisión que respete parámetros objetivos, lo cual, por lo menos, implicará procesos generales y preestablecidos; 2) en la búsqueda de la mejor elección, sobre una base de posibilidades plausibles y concretas; y 3 ) que los criterios anteriores se sitúen en parámetros de estabilidad y coherencia. ${ }^{27}$

Ahora bien, para hablar de la racionalidad en la toma de decisiones, pero en sede constitucional, no se puede adoptar un simple paralelismo con la teoría de la elección racional; no obstante, sí es posible señalar una conexión a través de los siguientes puntos: 1) por la marcada búsqueda de una racionalidad procedimental que reduzca la subjetividad de quienes deciden; 2) por el establecimiento de parámetros que conformen los proceso mediante los cuales se toman las decisiones; y 3) porque tanto en la elección racional como en la toma de decisiones en sede constitucional de una magistratura, las decisiones tienen un carácter plausible, fundamental y trascienden a la sociedad.

25 Sobre la acción social, véase Habermas, Jürgen, Teoría de la acción comunicativa, trad. de Manuel Jiménez Redondo, Madrid, 1999, t.I, pp. 351-391. Para un breve estudio y acercamiento a un concepto sociológico sobre la acción social, desde las perspectivas de Max Weber, Talcott Parsons, Alain Touraine y Anthony Giddens, véase Lutz, Bruno, “La acción social en la teoría sociológica: una aproximación”, Revista Argumentos, México, vol. 23, núm. 64, septiembre-diciembre de 2010.

26 Allingham, Michael, op. cit., p. 109.

27 Sobre la trascendencia de la toma de decisiones racionales, que repercute en la estabilidad y la coherencia en ordenamientos jurídicos y sistemas normativos, véase Peczenik, Aleksander, Derecho y razón, trad. de Ernesto Garzón Valdéz, México, Fontamara, 2000, pp. 41-52. 
JULIO CÉSAR MUÑOZ MENDIOLA

Así, en una magistratura constitucional se toman decisiones mediante un proceso racional, pues independientemente del valor intrínseco de las decisiones, por su carácter colectivo-fundamental con trascendencia jurídica y social, en esta sede, los jueces constitucionales deciden a través de una racionalidad procedimental; la cual se basa y estructura por una serie de parámetros objetivos como se verá más adelante.

En paralelo, es necesario esbozar lo que se entenderá por racionalidad judicial y señalar por qué es exigible en la aplicación del Derecho en general. En el año de 1973 en el caso Soraya (BVerfGE34,269), el Tribunal Constitucional alemán sostuvo en su sentencia que un juez debía de mantenerse alejado de la arbitrariedad, pues su decisión debía de descansar sobre una argumentación racional, mostrando de forma clara que, en un caso concreto, la norma escrita no cumplía con su función de resolver un problema jurídico de manera justa. ${ }^{28}$ De esta manera, se empezaba a configurar la necesidad de una justificación de las sentencias basada en la razón, pero en la razón práctica, como se sostuvo también en la misma sentencia; es decir, la resolución judicial debería de integrar las lagunas del orden jurídico atendiendo a los criterios de la razón práctica y a los fundados criterios generales de justicia de la comunidad. ${ }^{29}$

Esta argumentación basada en la razón práctica, para el ámbito de las magistraturas constitucionales, se presentaría como una necesidad que a sus operadores les sería más que exigible, ya que no sólo deberían de fundar sus resoluciones en el Derecho, sino también en la razón práctica, pues a través de la argumentación jurídica, como una forma de justificación relacionada con la razón y coincidente con el sistema objetivo de valores contenido en una Constitución, los jueces constitucionales deberían de fundamentar y justificar sus decisiones en sede constitucional. ${ }^{30}$

28 Schwabe, Jürgen, Jurisprudencia del tribunal constitucional federal alemán. Extractos de las sentencias más relevantes, trad. de Marcelo Anzola Gil y Emilio Maus Ratz, México, Konrad Adenauer Stiftung, 2009, p. 493.

29 Idem.

30 Sobre este punto, un juez constitucional no deja de fundarse en las normas jurídicas creadas por las asambleas representativas, pues también constituyen una fuente de razón práctica, lo cual se puede constatar en la deferencia hacia el legisla- 
Principalmente, porque en las magistraturas constitucionales es en donde las decisiones no sólo deben de descansar en una justificación interna, basada en la lógica formal, sino también en una justificación externa, basada en razones cognoscibles, es decir, lo más razonables para la sociedad en general. Esto puede ser entendido de mejor manera, si por racional en sede constitucional se entiende una proposición, una norma o una valoración que es justificable mediante una argumentación apropiada, la cual, a su vez, se basa en un determinado conocimiento y determinadas valoraciones. ${ }^{31}$

Consecuentemente, cabría formular la siguiente pregunta: ¿a qué tipo de conocimiento y valoraciones se ciñe el juez constitucional? La respuesta obvia sería al sistema objetivo de valores preestablecido (la Constitución). No obstante, el planteamiento persistiría en la medida en que ese sistema funciona como una norma que se interpreta, por tanto, implica para el juzgador constitucional, no sólo una actividad de creación o adjudicación del contenido constitucional, sino también de decisión cognitiva.

Por tanto, esa decisión, en gran medida, puede ser representada y demostrable por la argumentación jurídica, porque establece una aproximación del Derecho con la razón, ya que su propósito principal es dar contenido valorativo y práctico, pero, sobre todo, una justificación al Derecho mediante la institucionalización de la razón. ${ }^{32}$ Esta cuestión implicará asumir que, a nivel constitucional (al menos de manera plausible), existe la posibilidad de fundamentar valoraciones morales mediante la razón práctica; esto es, reconocer que existe un cierto objetivismo moral en un sentido débil, lo cual, en

dor al analizarse la exposición de motivos, la teleología, la coherencia y el lenguaje de esas normas en sede constitucional; sin embargo, esa justificación para una sentencia constitucional no es suficiente, porque, en muchas ocasiones, precisamente el objeto de análisis serán esas normas que han justificado una aplicación del Derecho. Sobre todo, si se toma en cuenta que la función de un juez constitucional es contrastar normas y actos con un orden objetivo de valores preestablecido (la Constitución).

31 Cfr. Wróblewski, Jerzy, Sentido y hecho en el..., cit., p. 46.

32 Véase Nava Tovar, Alejandro, La institucionalización de la razón. La filosofía del Derecho de Robert Alexy, México, Siglo Veintiuno, 2015. 
parte, refutaría posturas escépticas, relativistas y absolutistas de la moral.

Sin embargo, a pesar de que la argumentación es fundamental para las decisiones judiciales en general $\mathrm{y}$, en específico, para la toma de decisiones en sede constitucional, principalmente, porque la justificación de una decisión judicial es una manera de demostrar la racionalidad de la decisión y, al mismo tiempo, actúa como un control de esa racionalidad; ${ }^{33}$ pese a ello, la argumentación no representa el único factor que opera como parámetro objetivo en la toma de decisiones de un juez constitucional. En resumen, para este trabajo la racionalidad judicial en sede constitucional, se delimitará al proceso de toma de decisiones y los parámetros objetivos que lo conforman, los cuales plausiblemente constriñen y orientan al juzgador constitucional, al mismo tiempo que reducen espacios para la subjetividad y la arbitrariedad de este operador.

\section{LA TESIS DEL RESTRICTOR COGNITIVO Y SU VINCULACIÓN CON LA DECISIÓN DEL JUEZ CONSTITUCIONAL}

Una de las primeras cuestiones que debe tomarse en cuenta es la dimensión en donde se desarrollará el $\mathrm{RC}$, pues atendiendo a una división tridimensional de la problemática planteada, en este caso, la racionalidad y la irracionalidad de las decisiones de los jueces constitucionales, es posible identificar las siguientes dimensiones: 1) una dimensión meta-realista, donde se concibe que los jueces constitucionales deciden de forma irracional la mayoría de las ocasiones; 2) una dimensión idealista, donde se asume que los juzgadores constitucionales pueden formular decisiones racionales de forma absoluta e infalible, y 3) una dimensión plausible, en donde estos operadores constitucionales pueden decidir de la manera más racional posible mediante su proceso de toma de decisiones.

En este caso, el RC se situará en la tercera dimensión, pues se pretende establecer una postura intermedia (plausible), la cual se sustenta en que el proceso de decisión de un juez constitucional repre-

33 Wróblewski, Jerzy, The judicial application..., cit., p. 209. 
LA RACIONALIDAD JUDICIAL EN SEDE CONSTITUCIONAL

senta una serie de parámetros objetivos para construir y arribar a sus decisiones, ya que no sólo de forma teórica, sino también atendiendo a su concretización en la práctica judicial, determinará la racionalidad de sus decisiones en grados.

Por lo planteado, una segunda cuestión a tomar en cuenta es lo referente al proceso de toma de decisiones que se da en una magistratura constitucional, porque desde la perspectiva de este trabajo se le ha restado importancia y se le ha situado como plástico y supeditado a su operador; es decir, se piensa que ese proceso es operado arbitrariamente por los juzgadores constitucionales. ${ }^{34}$ Esto resulta erróneo, en el sentido que ese proceso es complejo y plagado de parámetros objetivos como se verá más adelante, al grado de incidir cognitivamente en sus operadores, justo en ese punto, el RC contribuye a reducir de manera significativa la subjetividad y arbitrariedad del juez constitucional. ${ }^{35}$

Consecuentemente, resulta indispensable una comprensión completa del proceso que se lleva a cabo en las magistraturas constitucionales, ya que, en sí mismo, es constitutivo de su propia racionalidad, porque su complejidad representa una especie de objetividad

34 Son varias las posturas que señalan una arbitrariedad de los juzgadores constitucionales, en donde se asume que los jueces sólo están motivados por cuestiones políticas y no legales o, en su caso, refieren que el juez constitucional es arbitrario por naturaleza, pues de otra forma no podría garantizar parte del contenido constitucional, asimismo, algunas críticas empatan la arbitrariedad con la discrecionalidad de este operador constitucional, en este caso, se dice que al tener facultades discrecionales por la revisión judicial, inevitablemente terminará siendo arbitrario. Sobre estas críticas véase Ossa Henao, Mario, La discrecionalidad judicial, Bogotá, Leyer Editores, 2015, pp. 25 y ss.; Posner, Richard, How Judges Think, London, Harvard University Press, 2008, pp. 125 y ss.; García de Enterría, Eduardo y Menéndez Menéndez, Aurelio, El Derecho, la ley y el juez. Dos estudios., Madrid, Civitas, 1997, pp. 80 y ss.

35 Para este trabajo, la subjetividad estará representada en las posiciones ideológicas, estratégicas y políticas que un juez constitucional pudiera tener, por su parte, la arbitrariedad, será entendida como la decisión sin sujeción a una norma, por ende, contrario al ordenamiento normativo, por ejemplo, esta definición puede ser encontrada en el artículo 9.3 de la Constitución española, cuando establece que la norma fundamental garantiza la interdicción de la arbitrariedad de los poderes públicos o, también, una decisión será arbitraria cuando no encuentra fundamentación en argumento racional. 
con pretensiones cosmopolitas, cuestión que se apoya en la premisa de que todos los sistemas jurídicos que hayan adoptado un diseño institucional de Estado Constitucional, esto es, que sean regímenes democráticos en donde opere el control judicial, contarán con ese proceso de decisión ${ }^{36}$.

Así, es posible identificar tres fases de ese proceso: 1) la que se refiere a las pre-condiciones del proceso, en donde se establece un filtro de los casos y controversias que los jueces constitucionales pueden conocer; 2) la que se refiere a la deliberación del proceso en un sentido amplio, donde los juzgadores constitucionales construyen y plasman gran parte de sus argumentos para resolver el caso; y 3) la que se refiere a las post-condiciones del proceso, por la cual los jueces constitucionales, de forma prospectiva, dimensionan el alcance de sus decisiones (véase figura 1).

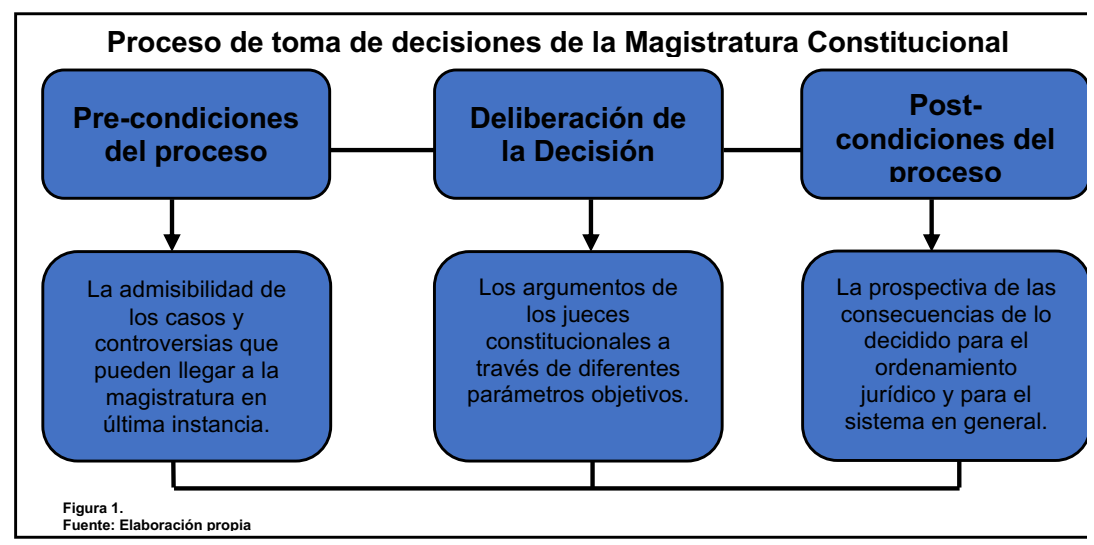

36 En este punto, es necesario tomar en cuenta la variable de la intensidad de operación del control judicial (véase supra la nota a pie de página número 9), así como la delimitación referente a las bases ideológicas y de diseño institucional que representa el paradigma constitucional (véase supra la nota a pie de página número 8), de otra forma, variables cómo la cultura jurídica de un sistema, escaparían de la proposición de este trabajo, por ejemplo, el caso del sistema jurídico japonés, en donde se contempla un diseño institucional similar al sistema norteamericano, en específico, la Corte Suprema de Japón tiene la facultad de ejercer control judicial de las leyes; no obstante, desde su creación sólo ha declarado inconstitucional poco más de ocho leyes, cuestión que podría encontrar explicación en la cultura de ese país que considera otro tipo de solución para los conflictos políticos e institucionales. 
Este esquema de tres bloques estructura el proceso de toma de decisión del juez constitucional, en donde la argumentación es una parte importante de la deliberación, pero no representa el único parámetro objetivo, pues en cada grupo existen parámetros diversos pero relacionados entre sí, los cuales, en conjunto, constituirán el $\mathrm{RC}^{37}$. Este diseño es importante desde una perspectiva teórica y práctica, porque representan elementos concretos que el juzgador constitucional emplea y enfrenta al realizar su función.

Ahora bien, antes de analizar cada bloque con sus respectivos parámetros, resulta pertinente aclarar que el establecimiento de una restricción debe de ser entendida en una perspectiva positiva y específica. Positiva, porque el RC no sólo vincula al juez constitucional a manera de constreñirlo a esos parámetros, sino también orienta su labor a través de los mismos; en otras palabras, no se refiere a una imposición epistémica para el juzgador. Por su parte, específica, ya que el RC no establece una restricción a la tarea cognoscitiva de ese operador en estricto sentido, sino específicamente al proceso de conocimiento y decisión que enfrenta el juzgador constitucional, pues este tiene una amplia libertad para conocer los casos, y su ejercicio cognitivo no se reduce únicamente a lo jurídico-constitucional, lo cual se ejemplifica en las llamadas Amicus Curiae, en donde el conocimiento del juez es apoyado en áreas o materias que implican diversos conocimientos especializados.

Un primer bloque es el de las pre-condiciones del proceso, en donde se encuentra un primer parámetro objetivo, el cual está representado en las normas constitucionales que facultan al juez constitucional para realizar el control judicial en el sistema, porque la mayoría de los textos fundamentales contemplan esa facultad de manera expresa o implícita, por tanto, no se puede poner en duda la institucionalidad de ese control y su reserva constitucional a favor del juzgador constitucional.

37 Por parámetros objetivos se deben de entender aquellos elementos dentro del proceso de toma de decisión del juez constitucional, los cuales no pueden dejar de observarse y no están puestos a capricho por este operador constitucional, por ejemplo, en el caso de la argumentación, el juez constitucional siempre argumentará su sentencia independientemente de la calidad y resultado de la misma. 
Ya que, tanto el control judicial como su operador, no pueden ir más allá de esas atribuciones constitucionales desde una perspectiva de diseño institucional, y esto es de suma importancia, porque tales atribuciones representan obstáculos infranqueables para que la magistratura o su operador sean auto generadores de casos, pues en la Constitución no existe ninguna atribución para ello, ni tampoco se le confiere algún tipo de facultad o poder para iniciar un proceso de constitucionalidad o algo semejante, inclusive, no les es permitido formular opiniones consultivas por iniciativa propia.

Por ello, para que opere el control judicial, este deberá de iniciarse por parte de un actor estatal, por particulares o por agentes sociales; además, esta promoción y ejercicio deberá de hacerse bajo ciertas condiciones de legitimación legal o constitucional. Así, este parámetro establece un límite autoevidente a la subjetividad y la arbitrariedad. Justamente, esto conectará con el siguiente parámetro, que se refiere a todas aquellas reglas que rigen la admisibilidad de esos casos que se promueven ante la magistratura. Estas reglas pueden estar contenidas en la Constitución, en leyes orgánicas y procesales o, inclusive, en la jurisprudencia o precedentes que rigen o se relacionan con la jurisdicción constitucional en cada latitud.

En este caso, el juez constitucional no sólo deberá de esperar a que se le formulen los casos, sino también deberá de analizar de manera oficiosa la pertinencia de ejercer, por decirlo así, la última instancia final de decisión del sistema, pues el acceso a esta jurisdicción se encuentra limitada a casos de trascendencia y excepcionales. En conclusión, ambos parámetros objetivos ejemplifican como el juzgador constitucional empieza a ser determinado en su proceso cognitivo, inclusive, antes de tomar sus decisiones, pues desde la promoción de los casos comienzan a limitarse los espacios de subjetividad y arbitrariedad.

Ya en el bloque de la deliberación se encuentra un primer parámetro que se refiere al objeto de la interpretación y la argumentación del juez constitucional, lo cual tiene una convergencia con sus objetos de tutela, pues el juzgador constitucional en un primer momento estará constreñido y orientado por los principios y derechos constitucionales; esto es, su función, por sí misma, es coherente y encaminada a un fin concreto: el fin constitucionalmente legítimo en abs- 
tracto. Esta cuestión es significativa, pues tal vez resulta obvio decir que los jueces constitucionales deben perseguir un fin constitucionalmente legítimo, pues su parámetro de contraste se presupone en la Constitución que interpreta y aplica, la cual, a su vez, también se presupone legítima por el acto constituyente; en otras palabras, la legitimidad de una Constitución no se cuestiona de forma constante, al menos desde una perspectiva institucional.

Justamente es allí donde la función del juez constitucional es coherente, pero además representa un parámetro que escapa a posiciones subjetivas y arbitrarias, pues trabaja sobre un parámetro aceptado y reconocido ex ante (la Constitución), en donde él no ha intervenido en su creación ni tampoco se ha arrogado la tarea de aplicarla y resguardarla. En otras palabras, el ejercicio de su función se da sobre una base objetiva, siempre orientada por ese fin constitucional abstracto (cada derecho y principio constitucional en concreto), lo cual no excluye que puede tornarse pragmáticamente subjetiva, ideológica y política (la posición meta-realista), pero gran parte de esta cuestión se situará fuera del proceso de decisión, en específico, se enfatiza cuando lo decidido es contrastado frente a las diferentes posiciones políticas o sociales (pluralismo en general), entiéndase que la racionalidad de una decisión del juez constitucional sólo se puede lograr en grados.

En ese mismo sentido, los derechos fundamentales y los principios constitucionales contienen una característica esencial, y es que en sí mismos representan una pretensión de objetividad y universalidad, advirtiéndose sus correspondientes matices en esta afirmación, porque estos derechos y principios contienen núcleos duros, prácticamente iguales en cualquier sistema jurídico que se ostente como un Estado constitucional de derecho. ${ }^{38}$

38 Sobre este punto, es necesario advertir un matiz y una limitante metodológica de este trabajo. El matiz se refiere a que un núcleo duro de un derecho fundamental o principio constitucional deberá de entenderse a partir de considerarlos cómo categorías propias del paradigma constitucional y su diseño institucional, es decir, esos derechos y principios, sólo dentro de ese paradigma, se consideran como presupuestos objetivos y universales al ser condiciones esenciales de existencia del Estado Constitucional (véase supra la nota a pie de página número 8), cuestión que no implica proponer una objetividad y universalidad absoluta en cualquier 
JULIO CÉSAR MUÑOZ MENDIOLA

Sobre esta cuestión, piénsese que cuando un juez constitucional ejerce la función de proteger la libertad de expresión, este derecho en su núcleo duro representará lo mismo en los Estados Unidos, España o Bolivia, porque su significado, en general, es garantizar la expresión de ideas a las personas, lo que se traduce en una convergencia irrefutable en cualquier sistema jurídico. Cuestión diferente es los límites y alcances que a este derecho se le dé en los diversos sistemas; no obstante, nuevamente, esa es una cuestión perteneciente a diversas variables contingentes que no pueden excluirse de forma absoluta. Lo importante es destacar que, en un primer momento, dentro del proceso de toma de decisión estos derechos representan parámetros objetivos muy sólidos.

De igual manera, los principios constitucionales encuentran ese mismo núcleo duro de los derechos fundamentales, piénsese en el

sistema jurídico y, más aún, en su desarrollo y aplicación práctica. Precisamente, la limitante metodológica, se relaciona con el matiz mencionado, pues esos núcleos duros se reducen a un esquema de justicia o jurisdicción constitucional en donde esos derechos y principios estén resguardados en una Constitución con fuerza normativa y supremacía en el sistema jurídico. En ambos casos, los núcleos duros se refieren a un significado y entendimiento mínimo de esos derechos y principios como un sistema de valores objetivo para el Estado Constitucional, en donde los jueces constitucionales los desarrollan a partir de un significado, lenguaje y entendimiento constitucional común, porque aún en sistemas jurídicos que de facto se contrapongan al diseño institucional constitucional, esos derechos y principios representan pretensiones para su desarrollo y su significado enmarcados en el texto constitucional, por ejemplo: la Constitución rusa prescribe una supremacía normativa constitucional y un reconocimiento de derechos fundamentales como el debido proceso y la presunción de inocencia, por mencionar algunos (artículos 15 y 49); la Constitución de Filipinas, que reconoce la garantía de los derechos humanos y la dignidad de las personas, entre otros derechos fundamentales (Sección II, artículo 11, Sección III, artículos 1o., 3o. y 5o. ); la Constitución de Rwanda, la cual prevé la supremacía constitucional, la prohibición de la pena de muerte, la igualdad ante la ley y la libertad de expresión (artículos 3o., 12, 14 y 15); la Constitución Cubana prevé una supremacía constitucional basada en la dignidad humana, así como derechos de igualdad de las personas y libertad de prensa, por mencionar algunos ( artículos 7o., 40, 42, 43, 44 y 55); la Constitución de Venezuela, que prevé un régimen democrático fundado en el pueblo, una supremacía constitucional y el reconocimiento y garantía de los derechos humanos de fuente internacional (artículos 5o., 7, 23 y 62). Las Constituciones de estos países pueden ser consultadas en: https:// constituteproject.org 
principio de división de poderes en España, Colombia y Canadá, en este caso, es innegable que en esas latitudes existe un base única que, en abstracto, determina que el poder público se divide para su ejercicio y su control, en otras palabras, sin ese piso mínimo el juez constitucional podría interpretar de cualquier forma ese principio, en cuyo caso, se estaría hablando de cualquier otra cosa pero no de la división de poderes ${ }^{39}$. En consecuencia, tanto los derechos fundamentales como los principios constitucionales representan parámetros objetivos en el proceso y, en ambos casos, al ser objeto y fin de la función del juzgador constitucional; también interfieren en su forma de conocer y decidir.

Un segundo parámetro en el bloque de la deliberación es el de la política judicial de la magistratura, ${ }^{40}$ pues esta política está cons-

39 Nuevamente, es necesario situarse dentro del paradigma del Estado Constitucional (véanse supra las notas a pie de página números 8 y 38), en donde la división de poderes constituye uno de sus presupuestos de conformación en los sistemas jurídicos que se ostenten dentro de ese paradigma, por tanto, cuando un juez constitucional usa como parámetros de fundamentación de sus sentencias, un principio constitucional como la división de poderes, él se encontrará constreñido a una categoría y un lenguaje propio de la cultura (o ideología si se prefiere) del paradigma constitucional, de otra forma, si ese juez no compartiera la aceptación de ese paradigma; tampoco compartiría el caracterizarse y desarrollar una función como juzgador constitucional.

40 Para este trabajo, la política judicial se refiere a un sistema que es propio de cada magistratura constitucional, en donde los jueces que integran este órgano y un determinado ordenamiento jurídico bajo el paradigma constitucional, deben de considerar su propia jurisprudencia con el paso de los años, pues contribuyen a crear un sistema propio que refleja su política judicial y jurídica en lo individual y como institución; en torno a la interpretación de la Constitución de un sistema jurídico. Precisamente, en este punto, la coherencia de la política judicial se refiere a su conformación lógica como sistema integrado por el precedente y la jurisprudencia que exigen deferencia de parte del juez constitucional y, por otra parte, porque el análisis de ese sistema, como parámetro objetivo, únicamente se refiere a su racionalidad procedimental y no al resultado de una decisión en sede constitucional. Sobre todo, si se toma en cuenta que existen variables políticas y culturales que inciden en las decisiones de una magistratura constitucional, las cuales tienen la característica innegable de ser ambivalentes en el resultado, porque al igual que cualquier decisión judicial su resultado, por lo menos, tendrá dos interpretaciones posibles. Un ejemplo de la política judicial como sistema, puede ser observado en la decisión de la Corte Suprema norteamericana en el caso Bostock vs. Clayton County 
JULIO CÉSAR MUÑOZ MENDIOLA

tituida por los precedentes o, en su caso, por la jurisprudencia, no sólo de los jueces constitucionales que integran la magistratura actualmente, sino también por las decisiones de los jueces que han formado parte de ella a lo largo de su historia, por lo cual, esa política no es una simple tradición histórica, sino un sistema que constriñe y orienta la decisión del juzgador constitucional. Esta política, si bien representa posiciones personales de los miembros de la magistratura (si se quiere utilizar ese término), al mismo tiempo, también representará una objetividad institucional, porque realmente no es una sola ideología o subjetividad la que crea esa política; sino una diversidad ideológica y subjetiva que, al final, converge y se une por la coherencia que representa el propio sistema de precedente o jurisprudencia.

Esta política judicial se conecta en gran medida con el parámetro de los derechos fundamentales y los principios constitucionales, ya que representará aspectos doctrinales, teóricos y prácticos de esos derechos y principios, sólo que esta política se configura como un límite intrainstitucional, el cual se ha gestado dentro de la magistratura, precisamente, con la finalidad de unificar coherentemente el fin constitucional que se persigue en este órgano. En este punto, el juez constitucional debe de interpretar y aplicar los derechos y los principios del texto constitucional a la luz de su propia política judicial, la cual no debería ser ignorada o desestimada por una nueva conformación de la magistratura o, en su caso, por un juez en lo individual.

Esto último es demostrativo de la objetividad y lo complejo del proceso que sigue el juez constitucional, sobre todo, si se tienen en

Georgia decidido el 15 de junio de 2020, en donde se dio una confrontación añeja entre originalismo y adaptación de los valores constitucionales, así como entre jueces liberales y conservadores, pues a pesar de que factores como la ideología judicial, política y cultural, posiblemente, fueron determinantes para la modificación de la política judicial de la Corte Suprema, al final, ese cambio siguió un proceso preestablecido y determinado al cual siempre se ciñe la Corte Suprema para conservar o cambiar un precedente; es decir, el proceso de decisión se basó en la lógica del sistema de precedentes (política judicial), independientemente del resultado o aceptación de lo decidido. Sentencia consultable en: https://www.scotusblog.com/ wp-content/uploads/2020/06/17-1618_hfci.pdf. 
cuenta los siguientes puntos: 1) por la deliberación que, en estricto sentido, se da hacia el interior de la magistratura a través de la argumentación racional; ${ }^{41}$ 2) por la fuerza que ejercen los precedentes o la jurisprudencia de la magistratura, sobre cada uno de los jueces que la conforman; y 3) por la coherencia implícita de la estructura de esa política judicial.

Un tercer parámetro objetivo en el bloque de la deliberación, es el llamado diálogo jurisprudencial, que de manera general se puede entender como una internacionalización tanto del diálogo de los jueces constitucionales en otras latitudes, como del diálogo de jueces regionales protectores de los derechos humanos. Este diálogo refuerza la tesis de que los derechos fundamentales y los principios constitucionales presentan núcleos duros, pues como se mencionó, representan una universalidad para todos los sistemas que se ostenten como democráticos, asimismo, esta cuestión simboliza la lógica de ese diálogo, ya que las magistraturas de diversas latitudes comparten experiencias teóricas y prácticas de la adjudicación del contenido constitucional.

Así, el diálogo jurisprudencial se sustenta en un cosmopolitismo constitucional que se construye a través de la argumentación y la interpretación que se da en las magistraturas constitucionales, pues en él subyace una práctica común en la protección de esos derechos y principios, pero, sobre todo, una metodología en la forma de argumentar las decisiones por parte de los jueces constitucionales, en este punto, se pude decir que esas metodologías, si bien no son uniformes en forma absoluta, sí comparten una orientación a través de la doctrina constitucional. ${ }^{42}$

41 Sobre esta cuestión, es necesario tomar en cuenta que hacia el interior de una magistratura constitucional como última instancia de decisión y como un órgano colegiado, en estricto sentido, siempre existirá una deliberación, inclusive, para el conocimiento y admisión de un caso que se resolverá, porque esa decisión también se discutirá y votará, por tanto, existirá una deliberación independientemente de la calidad o aceptación del resultado de la misma (véase supra nota a pie de página número 37).

42 Al referir una metodología en la forma de argumentar que orienta de manera uniforme a los jueces constitucionales, nuevamente es necesario situarse en el paradigma constitucional (véanse supra notas a pie de página 8 y 38), pues sólo en 
JULIO CÉSAR MUÑOZ MENDIOLA

Por supuesto, esta orientación no vincula con la misma fuerza que los precedentes y la jurisprudencia nacional, pero sí forma parte importante en la justificación de las decisiones de los jueces constitucionales. Piénsese que cuando un juez toma en cuenta lo decidido en otro sistema jurídico, introducirá de alguna manera un criterio ajeno a su voluntad y, en estricto sentido, a la voluntad de sus colegas en la magistratura.

Por tanto, ese criterio condiciona su decisión a dos aspectos importantes: 1) nuevamente a la coherencia, porque si se ha introducido un criterio en torno a un asunto decidido en otra latitud, por lógica, como mínimo deberá de seguirse esa ruta interpretativa, de otra manera el juez constitucional no lo habría introducido; y 2) ese criterio que el juez constitucional introdujo a la deliberación de la magistratura, por sí mismo, representará un alejamiento a alguna clase de posicionamiento estratégico, ideológico o político, ya que introduce una posible respuesta al caso que él no ha pensado o creado. Es decir, ese criterio supone una adherencia lógica por parte del juez constitucional, pero, al mismo tiempo, supondrá una visión ajena al caso en concreto, lo cual disminuiría la subjetividad del operador constitucional, ya que, si se quisiera hablar de un posicionamiento subjetivo o arbitrario, entonces, tendría que hablarse de una subjetividad y arbitrariedad que comparten todos los jueces constitucionales a nivel global.

Por último, un cuarto parámetro objetivo en el bloque de la deliberación, se refiere a las distintas racionalidades que debe de tomar en cuenta el juez constitucional en su decisión. Pues si en el ámbito

sistemas que comparten las categorías de análisis propias de ese paradigma, pueden compartirse metodologías similares como herramientas argumentativas hacia el interior de una magistratura constitucional, lo cual no significa que esas metodologías funcionen como una regla absoluta y observable en cualquier sistema y latitud, sino sólo destacar que, por ejemplo, la Corte Suprema de Israel, la Suprema Corte mexicana, la Corte Constitucional Colombiana, el Tribunal Constitucional alemán, el Tribunal Constitucional Plurinacional de Bolivia y el Tribunal Constitucional español realizan metodologías similares (juicio de proporcionalidad y razonabilidad), para el análisis de una norma que restringe un derecho fundamental. Pues, aun en sistemas como el norteamericano, en donde el diálogo jurisprudencial está prohibido por su Corte Suprema; existen metodologías similares (strict scrutiny y balancing aproaches). 
de la decisión judicial existe una diversidad de materias que participan en la toma de decisiones, en el ámbito de la decisión constitucional esas materias se vuelven aún más determinantes. En este punto, un juzgador constitucional no sólo toma en cuenta argumentos jurídicos, ya que los casos que involucran tanto derechos fundamentales como principios constitucionales tendrán una vinculación o repercusión con distintas materias.

Por ello, el juez constitucional está constreñido a no sólo tomar en cuenta esos aspectos, sino a comprender la propia racionalidad de estas materias, ya que la exigencia de sus decisiones es la de una respuesta que busque ser compatible con el sistema jurídico y lo más coherente posible a nivel jurídico, social y político; en otras palabras, la racionalidad científica, económica o política también determinan las decisiones de un juzgador constitucional.

Por ejemplo, un caso que decida sobre la constitucionalidad de la interrupción del embarazo no se reducirá a una serie de argumentos jurídicos, pues buscará también involucrar argumentos de tipo científico $^{43}$; por lo cual, el juzgador constitucional estará determinado por una racionalidad científica también. En ese mismo sentido, si el caso involucra la inconstitucionalidad de una contribución, por supuesto, la primera orientación del juez constitucional se dirigirá a un derecho o principio constitucional; no obstante, también deberá tomar en cuenta la racionalidad económica que subyace en esa contribución. Finalmente, piénsese en como la racionalidad política está concretizada en la deferencia hacia el legislador, lo cual no implica una decisión política, sino entender que un juzgador constitucional toma en cuenta la racionalidad política que opera en la asamblea representativa; esto es, para decidir si una ley es inconstitucional, este operador constitucional parte de las razones políticas que se plasmaron en la exposición de motivos.

Finalmente, en el bloque de las pos-condiciones del proceso, se encuentra un sólo parámetro objetivo, el cual se refiere al análisis

43 Si bien no existe una norma jurídica que exija involucrar argumentos científicos en las decisiones de los jueces constitucionales, también resulta cierto que, por lo complejo de los casos que llegan a una magistratura, los propios jueces buscan allegarse de especialistas en temas complejos que involucran aspectos científicos. 
JULIO CÉSAR MUÑOZ MENDIOLA

de las consecuencias de lo que se decide en una magistratura constitucional en última instancia. Este parámetro se caracteriza por la consciencia que guarda un juez constitucional sobre las implicaciones o las consecuencias de su decisión, no sólo para el ordenamiento jurídico, sino para todo el sistema jurídico. Cuestión que guarda una vinculación con las distintas racionalidades que participan en las decisiones en sede constitucional, pues de forma prospectiva, un juzgador constitucional deberá de vislumbrar las consecuencias jurídicas, económicas, políticas y sociales de los efectos de sus sentencias.

Efectos que no serán decididos de forma discrecional, sino que, por el contrario, se determinarán por tres aspectos importantes: 1) por las reglas que se le imponen jurídicamente al juez constitucional para establecer esos efectos, es decir, reglas constitucionales, legales o desde la política judicial de la magistratura constitucional, por las cuales se establecen parámetros y límites en esa tarea; 2) por la coherencia sistémica que deben de respetar esos efectos, esto es, tanto la decisión como sus efectos deberán de ser coherentes entre sí y con el sistema jurídico; y 3) por la presunción de colaboración que supone el cumplimiento de una sentencia de la magistratura constitucional, en otras palabras, la función de una magistratura no se reduce a una tarea de contrapeso, sino también a una función de colaboración compatible con un sistema democrático. ${ }^{44}$

En sumario, la tesis del RC se basa tanto en el aspecto de la complejidad del proceso de toma de decisiones, como en los distintos

44 La función colaborativa de una magistratura constitucional se puede ver en las sentencias dialógicas de la Corte Constitucional colombiana, por ejemplo, en la sentencia T-398/2019, en donde se garantizó el derecho fundamental a la salud menstrual de una mujer en situación de calle, pues en el caso se ordenó realizar acciones concretas a la administración pública, como la entrega mensual de toallas sanitarias a la mujer, no obstante, también se ordenaron acciones de carácter general, como la implementación de políticas públicas por parte de las Secretarías para identificar y proveer de esas acciones concretas a más mujeres en la misma situación. En este caso, se puede apreciar el aspecto de la colaboración, pues la Corte al ordenar a un organismo estatal que concretice el derecho fundamental de la mujer en situación de calle, implícitamente, requiere de la colaboración de más instancias públicas para extender esa concretización a más mujeres; lo cual es completamente aceptable en cualquier sociedad democrática. La sentencia puede ser consultada en: https://www.corteconstitucional.gov.co/relatoria/2019/T-398-19.htm. 
parámetros objetivos que estructuran cada bloque de ese proceso, lo cual establece un modelo teórico en torno a que el juez constitucional, durante todo su proceso de toma de decisiones, se encuentra orientado y constreñido cognitivamente, lo que reduce espacios para posiciones subjetivas o arbitrarias, pues en mayor medida estos parámetros operan en todas las decisiones que se dan en el seno de una magistratura constitucional (véase figura 2).

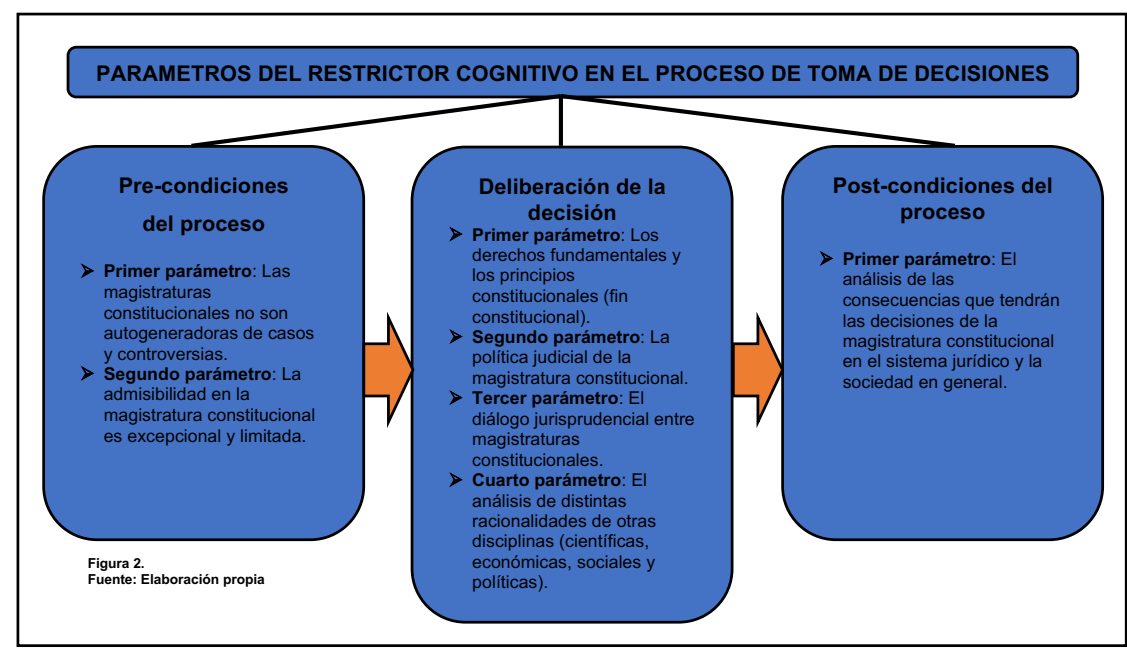

\section{CONCLUSIONES}

La epistemología jurídica aplicada representa una herramienta funcional y práctica para desarrollar análisis desde perspectivas teóricas que, como modelos mentales, cumplan con una finalidad de análisis real o práctico. Asimismo, el razonamiento judicial es una de las áreas donde concurren diferentes elecciones en torno a la adjudicación del Derecho, porque no sólo involucrará una decisión para justificar y aplicar normas, sino también las consecuencias de esa decisión; en este punto es donde diversos factores pueden e inciden en la decisión de un juzgador. 
Por otra parte, los sistemas jurídicos que se ostenten como democráticos, pueden ser estudiados de manera uniforme, pues a partir de su diseño institucional constitucional encuentran una convergencia en la estructura del control judicial, esto es, en el esquema de una magistratura constitucional, un juez constitucional y la aplicación práctica de ese control de forma más o menos fuerte.

Dentro de ese diseño, el papel de un juez constitucional se torna de suma importancia, ya que las decisiones que se toman en esa instancia constitucional representan decisiones colectivas fundamentales. Así, es posible hablar de un paralelismo con la teoría de la elección racional, porque en sede constitucional también existe la búsqueda de una racionalidad procedimental; el establecimiento de parámetros objetivos que conformen los procesos de decisión; y por la fundamentabilidad y trascendencia de las decisiones que se toman en esa sede para la sociedad.

Bajo esta perspectiva, el juez constitucional es un adjudicador del contenido constitucional con características técnicas únicas en el sistema jurídico, pues su función de decisión está determinada cognitivamente por un proceso de decisión complejo y plagado de parámetro objetivos. Consecuentemente, ese proceso será clave para determinar la racionalidad de sus decisiones y reducir espacios importantes de arbitrariedad y subjetividad en la toma de decisiones. En paralelo, ese proceso establecerá una postura intermedia (plausible), en oposición a las creencias de decisiones libres de cualquier subjetividad y arbitrariedad o, en el extremo contrario, por la idea de decisiones siempre subjetivas y arbitrarias.

Esta posición intermedia se apoya en la tesis del RC, la cual representa un modelo teórico en torno a la existencia de diversos parámetros objetivos que determinan el proceso cognitivo de un juez constitucional, ya que se puede establecer una racionalidad procedimental que opera de forma práctica, a través de tres bloques del proceso de decisión en sede constitucional, y que, en conjunto, constriñen y orientan la forma en que este operador constitucional toma sus decisiones. 


\section{FUTURAS INVESTIGACIONES}

Este trabajo pretende ampliar la forma de analizar las decisiones judiciales en sede constitucional y, además, impulsar futuras investigaciones en torno a: 1) la comprobación de la aplicación del RC en diferentes latitudes, ello, a través del análisis de casos; 2) el grado de aplicación del RC en una decisión, también mediante el análisis de casos concretos; y 3) la posibilidad de establecer una división entre el proceso de decisión y su resultado en sede constitucional, con la finalidad de determinar si se pueden conectar ambas de forma coherente, o si son independientes en la adjudicación del contenido constitucional.

\section{REFERENCIAS}

Aвitbol, Pablo y Botero, Felipe, "Teoría de la Elección Racional: estructura conceptual y evolución reciente", Revista Colombia Internacional, Colombia, núm. 62, julio-diciembre de 2005.

ACKerman, Bruce, La constitución viviente, trad. de Carlos M. Enrigue, España-Madrid, Marcial Pons, 2011.

Allingham, Michael, La teoría de la elección racional. Una breve introducción, trad. de José Ventura López, España-Madrid, Alianza Editorial, 2011.

BARAK, Aharon, Un juez reflexiona sobre su labor: El papel de un tribunal constitucional en una democracia, trad. de Estefanía Vela Barba, México, Suprema Corte de Justicia de la Nación, 2008.

BARon, Jonathan, Morality and Rational Choice, Boston, Springer, 2001.

Bernal Pulido, Carlos, El derecho de los derechos. Escrito sobre la aplicación de los derechos fundamentales, Bogotá, Universidad Externado de Colombia, 2005. 
CÁceres Nieto, Enrique, Pasos hacia una teoría de modelos mentales coherentistas-conexionistas del razonamiento judicial en la tradición romano-germánico, México, UNAM, 2017.

CÁceres Nieto, Enrique, "Dispraxis jurídica. Modelos Mentales y Constructivismo Jurídico Complejo", en Calle Valle, Fernando et al. (coords.), Dispraxis, 2a. ed., México, UNAM, 2012.

CÁCEREs Nieto, Enrique," Epistemología Jurídica Aplicada”, en FABRA ZAmora, José Luis y SPEctor, Ezequiel (coords.), Enciclopedia de filosofía y teoría del Derecho, México, UNAM, 2015, vol. III.

ELSTER, Jon, Razón y racionalidad, trad. de Horacio Pons, ArgentinaBuenos Aires, Editores Amorrortu, 2014.

ELSTER, Jon, Las limitaciones del paradigma de la elección racional. Las ciencias sociales en la encrucijada, trad. de Julian Garza, en Casas Pardo José (ed.), España-Valencia, Institutio Alfons El Magnanim, 2000.

ELSTER, Jon, Juicios salomónicos. Las limitaciones de la racionalidad como principio de decisión, trad. de Carlos Gardini, EspañaBarcelona, Gedisa, 1991.

ELSTER, Jon, Ulises y las sirenas: estudios sobre racionalidad e irracionalidad, trad. de Juan José Utrilla, México, Fondo de Cultura Económica, 1989.

García de Enterría, Eduardo y Menéndez Menéndez, Aurelio, El Derecho, la ley y el juez. Dos estudios, España-Madrid, Civitas, 1997.

HABERMAS, Jürgen, Teoría de la acción comunicativa, I. Racionalidad de la acción y racionalización social, trad. de Manuel Jiménez Redondo, España-Madrid, 1999.

HowARD, Williams, "En la sombra de la crítica de la razón pura: los resultados de la filosofía crítica llevados a la filosofía legal y política de Kant", trad. de Isabel Gamero y Macarena Marey, Las Torres de Luca. International Journal of Politicial Philophy, España-Madrid, vol. 7, núm. 13, 2018. 
Laudan, Larry, Truth, Error and Criminal Law, Nueva York, Cambridge University Press, 2006.

LuTZ, Bruno, "La acción social en la teoría sociológica: una aproximación”, Revista Argumentos, México, vol. 23, núm. 64, septiembre-diciembre de 2010.

NAva Tovar, Alejandro, La institucionalización de la razón. La filosofía del Derecho de Robert Alexy, México, Siglo Veintiuno, 2015.

Ossa Henao, Mario, La discrecionalidad judicial, Colombia-Bogotá, Leyer Editores, 2015.

PALACio Díaz, Alejandro, La razón contra sí misma. Razón y justicia en siglo XX, México, Claves Latinoamericanas, 2000.

PeCzeniK, Aleksander, Derecho y razón, trad. de Ernesto Garzón Valdéz, México, Fontamara, 2000.

Posner, Richard, How Judges Think, London, Harvard University Press, 2008.

RAWLS, John, El derecho de gentes y una revisión de la idea de razón pública, trad. de Hernando Valencia Villa, España, Editorial Paidós, 2001.

SchwaBe, Jürgen, Jurisprudencia del Tribunal Constitucional Federal Alemán. Extractos de las sentencias más relevantes, trad. de Marcelo Anzola Gil y Emilio Maus Ratz, México, Konrad Adenauer Stiftung, 2009.

SuÁRez Romero, Miguel Ángel, "La argumentación jurídica y el pensamiento de Luis Recaséns Sichez. Un análisis retrospectivo", Luis Recaséns Siches: Homenaje, México, UNAM, Facultad de Derecho, 2012.

TAYLOR, Charles, "La sola razón”, trad. de Gabriel García Jolly, Revista de Filosofía Open Insight, México, vol. IV, núm. 10, julio-diciembre de 2015.

Wróblewski, Jerzy, Sentido y hecho en el Derecho, trad. de Leonel Castillo González, México, Fontamara, 2001.

Wróblewski, Jerzy, The Judicial Application of Law, The Netherlands, Kluwer Academic Publisher, 1992. 